uniform leaching of salts during preirrigations, and many farmers now use sprinklers for that task before switching to surface methods during the season. Some farmers combine gated pipe with earthen head ditches to reduce the capital cost of improved surface methods while reducing the number of ditches required in each field. These improvements in irrigation methods are partly responsible for increases in the yield of cotton and other crops that respond to improvements in irrigation distribution uniformity. They have also helped to reduce deep percolation and the volume of drain water collected in subsurface drainage systems.

Farmers will continue to implement improvements in surface irrigation methods, and they will purchase gated pipe and sprinklers when these systems can be justified economically. Public policies that provide low-interest loans or other incentives for the purchase of higher technology systems reduce the farm-level annual capital cost of these systems significantly. However, the labor and energy requirements of gated pipe and sprinkler systems will continue to limit the adoption of these irrigation methods for field crops. Many farmers have discovered that the most cost-effective strategy for reducing irrigation costs is to manage surface irrigation systems more intensively. Research that develops further improvements in surface methods will enhance farm-level efforts to improve water management and reduce subsurface drain water while maintaining economic viability.

D. Wichelns is Associate Professor, Department of Resource Economics, University of Rhode Island; L. Houston is Natural Resource Economist, Kingston, Rhode Island; D. Cone is Manager, Broadview Water District, Firebaugh, CA; Q. Zhu was Graduate Student, University of Rhode Island, and now is Research Scientist, California Health Foundation, Sacramento; and J. Wilen is Professor, Department of Agricultural Economics, UC Davis.

This research was supported by the California and Rhode Island Agricultural Experiment Stations, the USDA Cooperative State Research Service and the Water Conservation Office in the California Department of Water Resources.

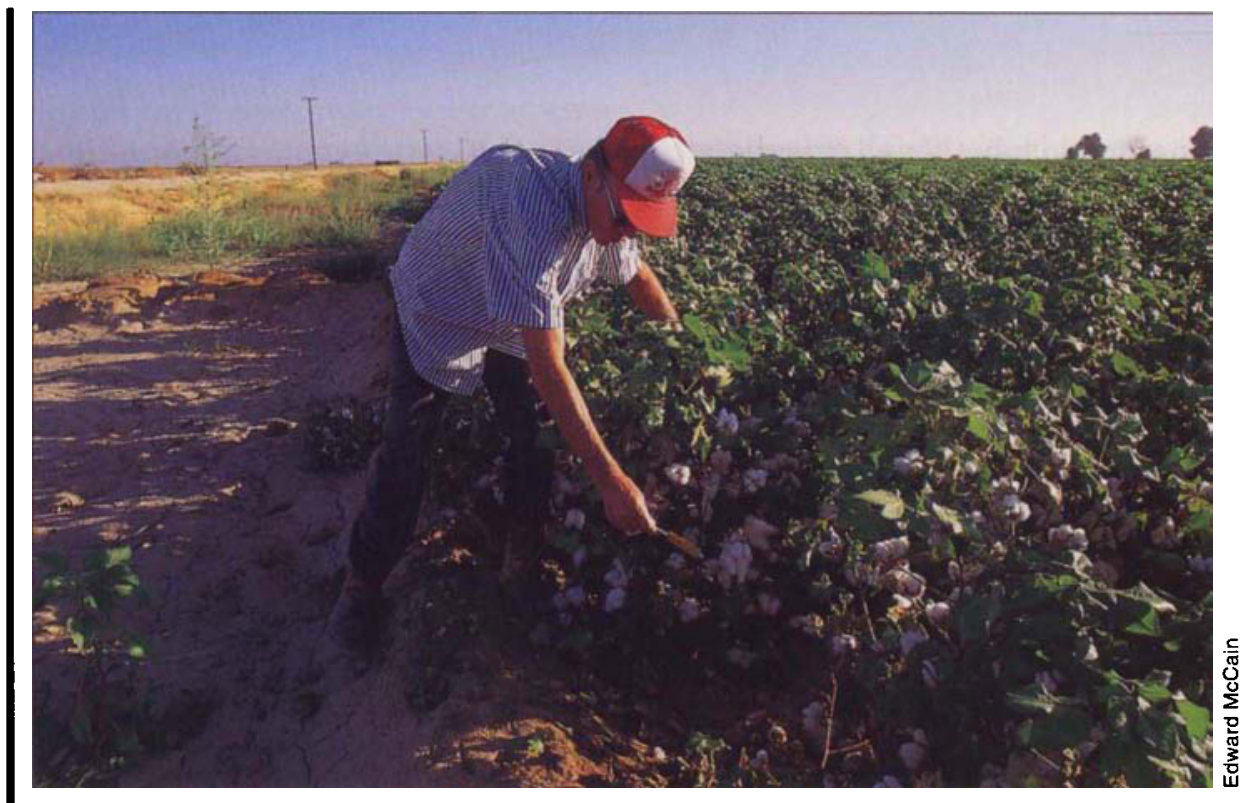

\title{
Silverleaf whiteflies show no increase in insecticide resistance
}

\author{
Steve Castle 」 Tom Henneberry 」 Nick Toscano \\ Nilima Prabhaker 」 Steve Birdsall 」 Dick Weddle
}

The silverleaf whitefly (Bemisia argentifolii Bellows \& Perring) continues to be a difficult pest to control in California's desert valleys. To gain a better understanding of the possible role that insecticide resistance plays in its annual outbreaks, a resistance monitoring program was established to document susceptibilities of whiteflies to various insecticides through time. Continuous monitoring during 1993 and 1994 detected no trend toward higher resistance levels. Higher toxicities of insecticide mixtures compared to single insecticides were regularly observed in bioassay results. Various factors including diverse insecticide use and altered cropping patterns may have helped to avoid serious insecticide resistance problems in the Imperial Valley so far.
The silverleaf whitefly became the predominant pest of agriculture in the Imperial Valley with its initial major outbreak in 1991. Although there are good indications that this new whitefly species had been present on melons and cole crops the previous year, it wasn't until the summer and fall of 1991 that its full destructive potential was realized. The damage to agriculture was perhaps unprecedented in terms of the breadth of crops attacked and the losses incurred.

Since 1991, the silverleaf whitefly has continued to ruin many crops despite intense efforts to manage populations by all methods, including reducing crop acres, using insecticides and practicing good crop sanitation. In 1992 planted cotton acreage was reduced to half of the previous year's 12,370 acres, fall melon production was eliminated, and dry-down of thousands of acres of alfalfa was implemented, all in voluntary cooperation to limit whitefly population. Never- 


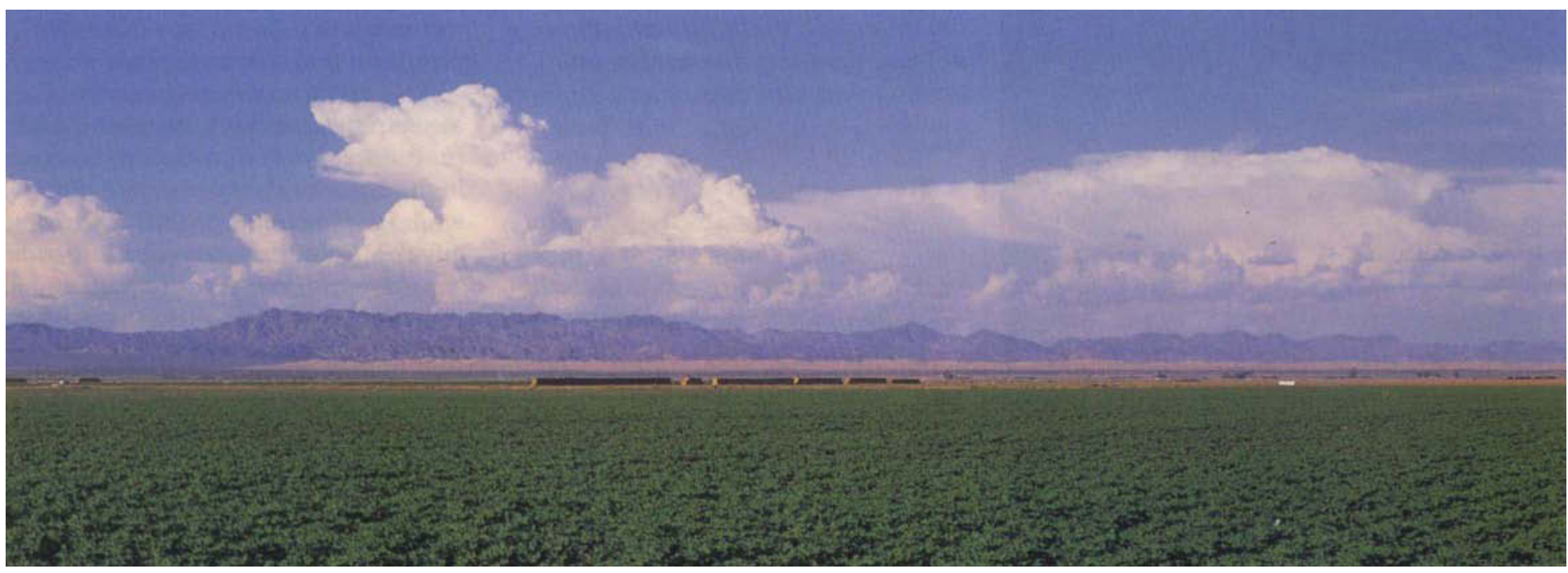

Left, seasonal biologist Howard Jencks collects adult whiteflies from a cotton field to monitor for insecticide resistance.

\section{Above, cotton production in the Imperial Valley has improved significantly since the first outbreak of silverleaf whiteflies in 1991. A cooperative program for monitor- ing insecticide resistance has helped to confirm that many insecticides remain highly effective against whiteflies.}

theless, whitefly numbers increased to extreme levels by midsummer, resulting in low yields and sticky cotton, an undesirable condition caused when whitefly-produced honeydew (excreta) falls on cotton lint.

High whitefly populations persisted into the fall lettuce and cole crop season, forcing heavy reliance on insecticides to limit infestations. In 1993 and 1994, a pattern of rapid increase of whitefly populations in spring melons continued, with spillover into cotton fields occurring at the time of melon harvest in June. Aggressive management of whiteflies in cotton with insecticides was aided in 1994 with the registration of fenpropathrin (Danitol) and amitraz (Ovasyn), leading to improved yields over previous years. However, whiteflies were still too abundant each year for fall melon production, which has been all but abandoned in the Imperial Valley.

Causes of the persistent outbreaks of silverleaf whitefly populations each summer and fall in the Imperial Valley over the last 4 years are being intensively investigated. In addition to trying to better understand the biology of this insect, researchers are pursuing various pest management solutions. The extraordinary ability of the silverleaf whitefly to colonize and disperse among a wide range of wild, cultivated and ornamental plants makes it an exceptionally difficult target for a management strategy that is heavily dependent on one method of control. A long-term, stable solution will most likely involve a creative integration of cultural, chemical and biological control methods.

At the present time, however, few management options are available apart from spraying insecticides to curb whitefly populations. In crops that are especially susceptible to whitefly colonization, such as cotton and melons, episodes of heavy exposure to insecticides are likely to occur. Moreover, because whiteflies are present year-round in the Imperial Valley on a sequence of crops, there is potential for continuous exposure of their populations to insecticides. This pattern of intensive, persistent insecticide use clearly presents a danger of insecticide resistance developing in whitefly populations. Occurrences of high resistance levels to organophosphate and pyrethroid insecticides in sweet potato whitefly populations were documented in the Imperial
Valley and other regions of the world during the 1980s.

\section{Resistance monitoring}

The 1991 outbreak in the Imperial Valley brought swift recognition of the need to determine the status of insecticide resistance in silverleaf whitefly populations. It was further recognized that as long as insecticides were to play an important role in efforts to control whiteflies, there should be ongoing testing to keep current on the responsiveness of whitefly populations to various insecticides. By making such information available, growers and pest control advisors might be better able to participate in efforts to delay widespread resistance to insecticides. Treatment decisions made with an awareness of trends in relative susceptibilities of whitefly populations to various insecticides could be an important step toward a resistance management program and the long-term stable management of whiteflies.

To put these ideas into practice, an insecticide resistance monitoring program was implemented through the cooperative efforts of USDA-ARS, UC Riverside, the Imperial County Agricultural Commissioner's Office, and the Imperial County Whitefly Management Committee. The scientists have been responsible for developing the sampling and bioassay procedures used to monitor resistance, while the Agricultural Commissioner's office 
LC90 levels relative to 1 . For example, if probit analysis of bioassay results for compound $X$ gives an LC 90 value of 0.40 , then we understand that there is a statistical probability that $90 \%$ of whitefly test subjects should be killed at a dosage of 0.40 , or $2 / 5$ of the top label rate. This representation allows those working in chemical control to relate dose-mortality data directly to the formulated product they use in the field (see sidebar).

Monitoring whitefly populations on a weekly basis makes it possible to detect changes in susceptibilities to insecticides. It is equally important to monitor variations in different fields or parts of the valley. Insecticide regimens may vary drastically from one field to the next and lead to more rapid development of resistance.

Therefore our monitoring program has attempted to sample randomly selected fields in various parts of the valley as a precaution against localized areas of resistance. This approach by no means guarantees that resistance development originating in one portion of the valley will be detected. But at least it spreads the effort around the valley where variations in cropping patterns may result in differential insecticide selection pressure on local populations.

\section{Insecticide evaluations}

Our most extensive data sets are for two compounds, bifenthrin and endosulfan. Both of these compounds are widely used to combat whiteflies and
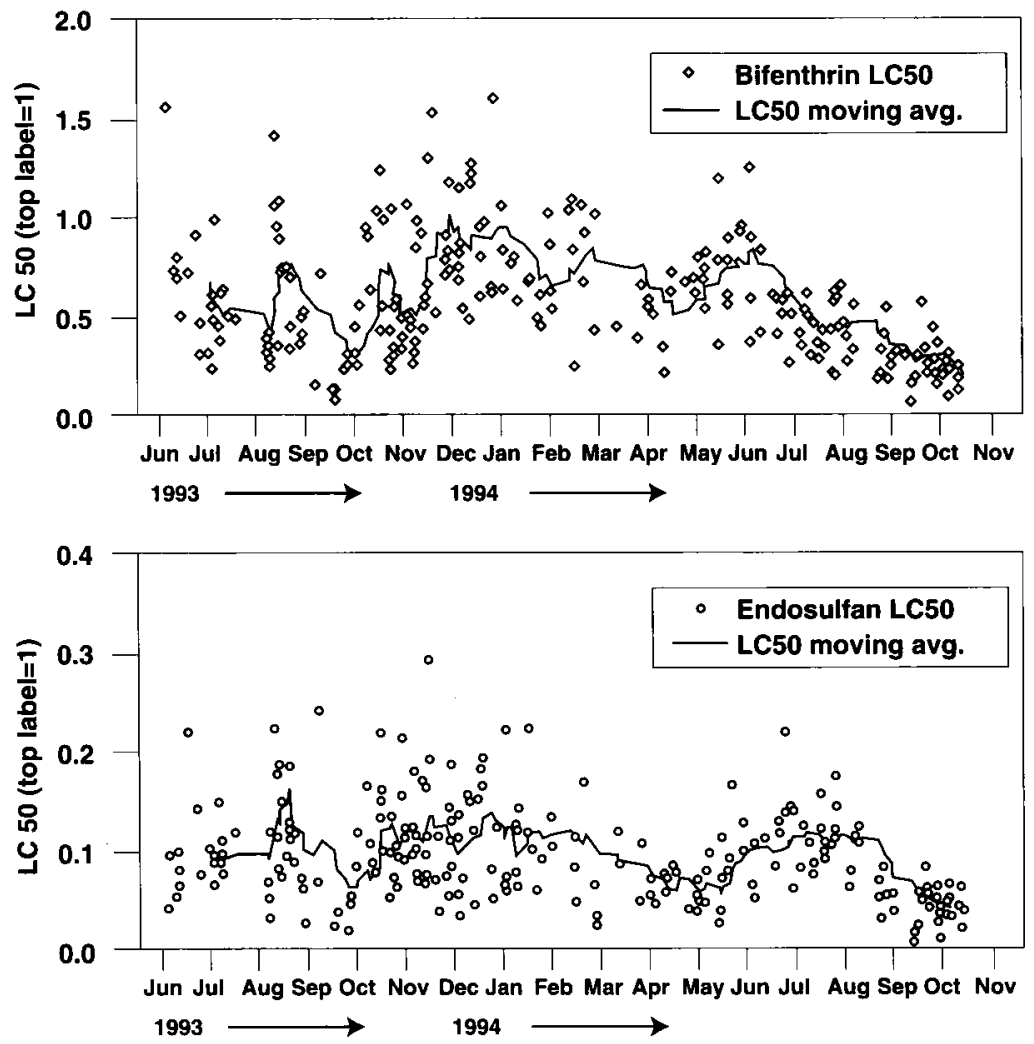

*Fig. 1. Results of bioassays conducted on field-collected whiteflies between June 1993 and October 1994 using (a) bifenthrin $(n=235)$ and $(b)$ endosulfan $(n=253)$. The solid line in each graph represents a 10-point moving average.

*The toxicological data presented in figures 1 through 3 are examples of dose-response data. The response of adult whiteflies to a range of doses of different insecticides has been measured by scoring the number of dead whiteflies at each dose. These data are treated statistically using probit analysis. This procedure yields a regression line from which values at different points along the line are generated. These points predict, at an assigned probability level, what proportion of the population will die at a given dosage. These graphs use the point along the line known as the "LC50," or "lethal concentration to $50 \%$ of the subjects." This is the insecticide dose that is lethal to $50 \%$ of the population.

Newsletter draws attention

to potential of insecticide resistance

Keeping growers and pest control advisors informed of insecticide resistance levels in whitefly populations is an important objective of our resistance monitoring program. To communicate current information on how whiteflies are responding to insecticides, we started a weekly newsletter.

Beginning in October 1993, we sent the newsletter to growers and pest control advisors involved with the cultivation of cole crops - including broccoli, cauliflower and cabbage which are suitable hosts for the silverleaf whitefly and are vulnerable to large populations of dispersing whiteflies during the fall. To spread our efforts across the area of cole crop plantings, we arbitrarily designated four regional quadrants within the Imperial Valley, and selected two fields from each quadrant for continuous weekly monitoring. We sampled for whiteflies Monday through Thursday to complete the bioassays by Friday. LC90 values were extracted for each insecticide and entered into a table according to quadrant. This table was included in the newsletter, which was mailed by the following Monday.

The toxicology data from the resistance monitoring survey were presented as LC90 values (the "lethal concentration" of an insecticide at which $90 \%$ of the whiteflies are killed) in the belief that growers and PCAs would be more interested in the rates that produced $90 \%$ mortality rather than the more customary LC50 values. In addition, concentrations of insecticides required to attain a given LC90 value were expressed in terms of label rates for each compound rather than as a unit of weight per volume. This was accomplished by setting the highest permissible rate of an insecticide on a particular crop to 1 , and then mixing all doses used in a bioassay relative to the top label rate. The top dose for some compounds exceeded the top label rate. In the newsletter, those compounds requiring their highest doses to be mixed at a concentration greater than the top label rate are identifiable by LC90s greater than 1 . 


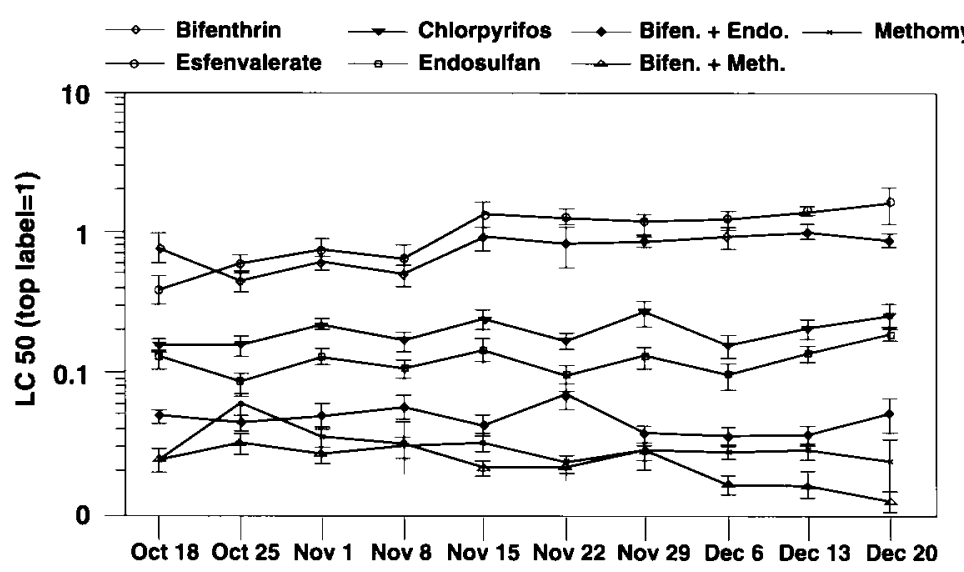

Fig. 2. Comparative mean ( $\pm S E$ ) LC50s of five insecticides and two insecticide mixtures from bioassays on adult whiteflies collected from eight different cole crop fields in the Imperial Valley over 10 consecutive weeks in 1993. ('See note, Fig. 1)
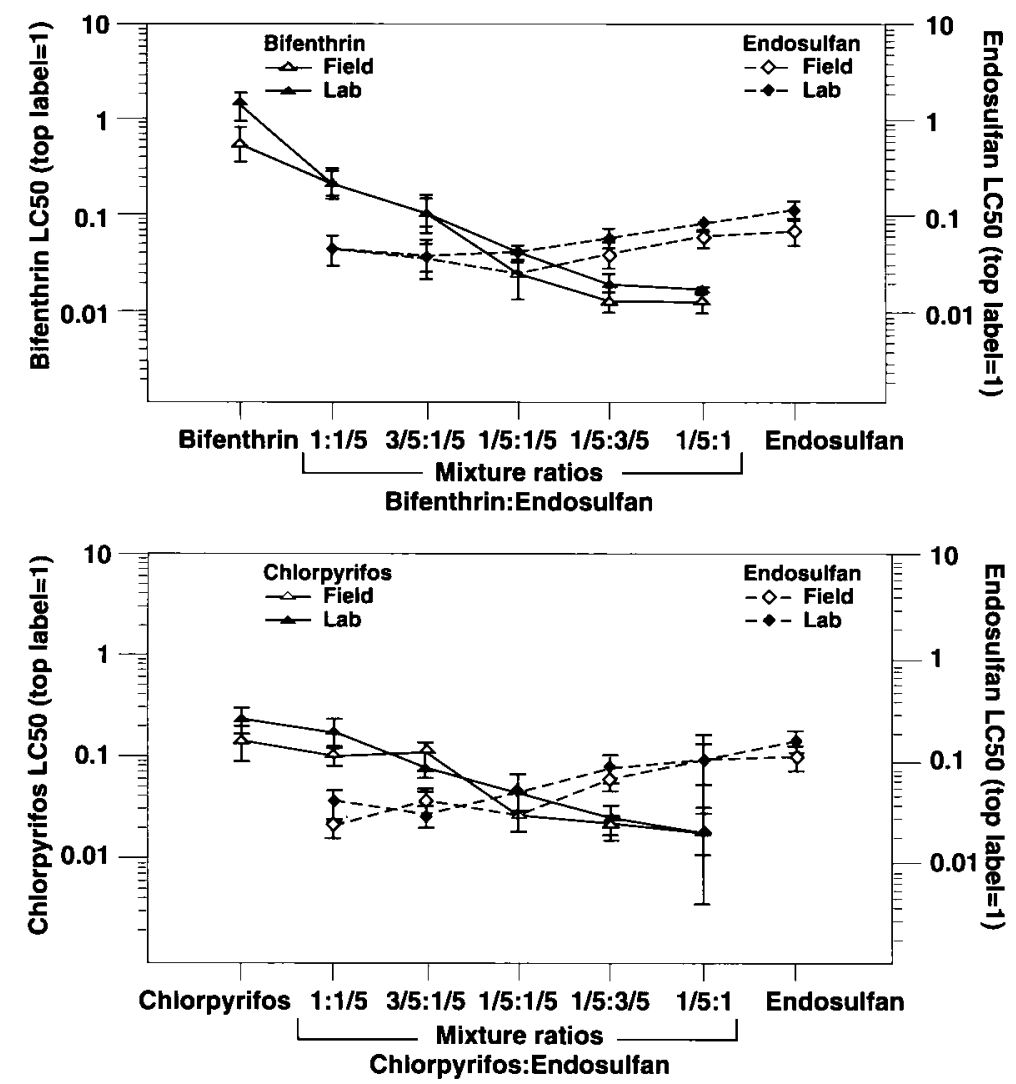

Fig. 3. LC50s ( \pm upper $95 \%$ fiducial limits) for (a) bifenthrin and endosulfan separately and in mixtures of varying ratios and (b) chlorpyrifos and endosulfan separately and in mixtures of varying ratios. Two sources of whiteflies, one from a laboratory colony (lab) and the other from a cantaloupe field, were used in each experiment. A value of 1 is equivalent to top label rate of the insecticides; fractions of $1(3 / 5,1 / 5)$ indicate that portion of the top label rate. (*See note, Fig. 1)

are often used together as a mixture. The scatter of points representing LC50 values shown in figures $1 \mathrm{a}$ and $1 \mathrm{~b}$ indicates variation in the response of whiteflies to both compounds, but the overall trend indicated by the moving average (solid line) shows no consistent progression to higher levels. Endosulfan has proven to be more toxic than bifenthrin when each is used individually. The LC50 values for endosulfan were consistently well be- low the top label rate, whereas LC50 values for bifenthrin often were greater than its top label rate during the 1993-1994 monitoring period.

Periodic bioassays of whiteflies collected from various cotton fields in 1993 using compounds or mixtures other than bifenthrin and endosulfan indicated high susceptibilities of whiteflies to certain insecticides. We decided to intensively evaluate some of these compounds by including them in the weekly monitoring. Beginning in October 1993, along with bifenthrin and endosulfan, methomyl (Lannate), chlorpyrifos (Lorsban) and esfenvalerate (Asana) were added to the monitoring survey. Also included were two mixtures, bifenthrin + endosulfan and bifenthrin + methomyl, for a total of seven treatments. Eight fields of cole crops from different parts of the valley were sampled 10 consecutive weeks for whiteflies. As shown in figure 2, the bioassay results for five of the seven treatments were generally consistent throughout the 10-week period.

For the pyrethroids bifenthrin and esfenvalerate, an increase in the mean LC50s occurred in mid-November and remained near this level for the duration of the monitoring period. Of the individual compounds, methomyl was the most toxic to whiteflies, followed by endosulfan, chlorpyrifos and the pyrethroids bifenthrin and esfenvalerate. Both of the insecticide mixtures were consistently very toxic. However, the combination of bifenthrin and endosulfan was much more toxic than either compound alone, whereas the bifenthrin and methomyl combination did not substantially increase the toxicity observed when methomyl was used separately.

Imperial Valley growers often depend on insecticide mixtures to control whitefly infestations. Although information from field trials and commercial treatments has helped to establish which mixtures are effective, other combinations of insecticides are sometimes used in the absence of any efficacy information. Moreover, scant information is available on whether insecticides mixed in ratios other than 1:1 are toxic to whiteflies. To investi- 
gate this, we examined the combinations of bifenthrintendosulfan and chlorpyrifos+endosulfan mixed at ratios of $1: 1 / 5,3 / 5: 1 / 5,1 / 5: 1 / 5,1 / 5: 3 / 5$ and $1 / 5: 1$, with 1 equal to the top label rate for each insecticide. Whiteflies collected from an untreated melon field and from a laboratory colony were tested separately, two replications per source, with the total number of insects tested for any one treatment ranging from 623 to 1,255 for the bifenthrin+endosulfan series and from 859 to 1,266 for the chlorpyrifos + endosulfan series.

There was an overall trend of lower LC50 values (higher toxicities) for each insecticide when used as part of a mixture than when used alone (fig. 3).

This pattern was most pronounced for bifenthrin as the toxicities of the mixture treatments increased with higher parts of endosulfan (fig. 3a, left to right). In contrast to bifenthrin, increases in toxicities of the various mixtures compared to endosulfan alone were not as steep, and there were no significant changes in toxicities with higher parts of bifenthrin compared to equal parts of bifenthrin and endosulfan (fig. 3a). A similar pattern was observed for both chlorpyrifos and endosulfan and their respective mixtures (fig. 3b).

These results support what is generally recognized about the synergism that occurs when a pyrethroid is mixed with an insecticide from a different class. In this example, the LC50 of bifenthrin alone was 22 -fold greater than the LC50 of equal parts (1/5:1/5) bifenthrin+endosulfan for the field strain, and 34-fold greater for the lab strain. In contrast, the LC50 of endosulfan alone was only about 3 -fold greater than the LC50 of equal parts bifenthrin+endosulfan. In both cases, however, substantially smaller amounts of total insecticide in the mixture treatments produced significantly higher mortality compared to either bifenthrin or endosulfan alone.

\section{Conclusions}

Confronted with extremely high whitefly numbers in the Imperial Valley the past 4 years, there has been a general assumption that resistance to insecticides precluded adequate con- trol of whitefly populations. Our extensive set of bioassay data from field-collected whiteflies indicates that whiteflies remain susceptible to many of the most commonly applied insecticides, especially when used as mixtures. Moreover, the resistance monitoring data do not show any sustained progression toward insecticide resistance in whitefly populations.

The findings from the resistance monitoring survey are supported by field-trial results showing that various insecticides used alone and / or as a mixture are still capable of providing season-long control, even under extreme whitefly pressure. In commercial cotton fields in 1994, management of whiteflies with insecticides produced the highest yields and cleanest cotton since the initial outbreak in 1991, despite intense immigration from melon fields. Altogether, these findings point to the conclusion that insecticides remain a powerful method of combating whiteflies.

Having dodged serious insecticide resistance problems thus far in the Imperial Valley, it is crucial that the agricultural community remain alert to signs of resistance development in the future. Insecticide use practices and cropping patterns in the Imperial Valley may have provided de facto resistance management up to this time. The pervasive use of insecticide mixtures, the alternation among different insecticide classes between crops, and the availability of extensive areas of essentially insecticide-free crops (alfalfa), ornamentals and weeds (thus conserving susceptible whiteflies), are all examples of strategies for managing insecticide resistance.

We are experimentally pursuing these strategies and others to try to determine the best approach for managing insecticide resistance in whiteflies. In the meantime, growers and PCAs should remain conservation-minded about protecting insecticide efficacies by using alternative approaches to whitefly control when possible, following action-thresholds developed for specific crops and rotating among insecticide classes to avoid selecting for resistance to a particular chemistry.

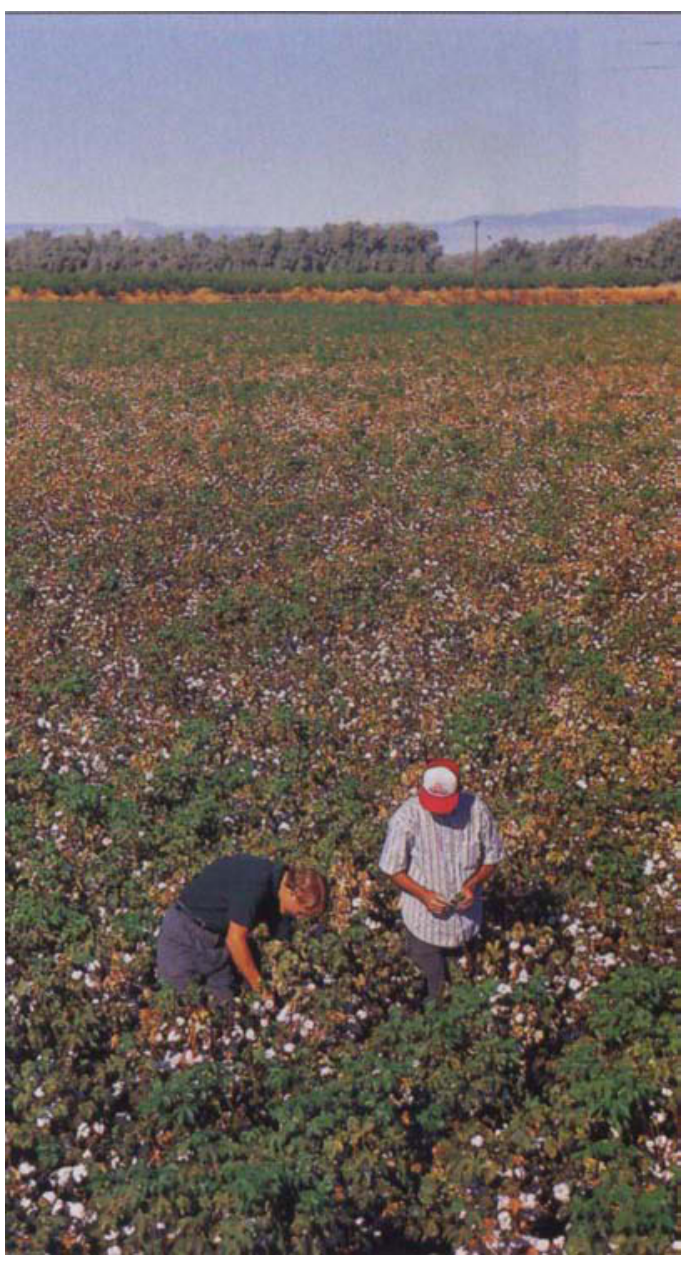

Researchers monitor insecticide resistance of whiteflies in a cotton field heavily damaged by whitefly infestations.

S. Castle is Research Entomologist, USDA-ARS, Brawley; T. Henneberry is Laboratory Director, USDA-ARS, Western Cotton Research Laboratory, Phoenix, AZ; N. Toscano is Cooperative Extension Entomologist, and N. Prabhaker is Postdoctoral Associate, Department of Entomology, UC Riverside; and S. Birdsall is Agricultural Commissioner, and D. Weddle is Entomologist, Imperial County Agricultural Commissioner's Office, El Centro.

Special thanks to Howard Jencks for his manifold contributions to the program. Thanks also to Jolene Carson, Brent Bolin and Shelly Osuna for their assistance with resistance monitoring. This research was supported in part by Imperial County Whitefly Management Committee; Cotton Incorporated; and the Insecticide Resistance Action Committee (IRAC).

For details on the silverleaf whitefly, see November-December 1991, JanuaryFebruary 1992 and January-February 1993 issues of California Agriculture. 